\title{
Artigo/Article
}

\section{Presença de culicídeos em município de porte médio do Estado de São Paulo e risco de ocorrência de febre do Nilo Ocidental e outras arboviroses}

\author{
The presence of Culicidae species in medium-sized cities in the State of São Paulo, Brazil and \\ the risk of West Nile fever and other arbovirus infection
}

\author{
Margareth Regina Dibo ${ }^{1,2}$, Regiane Maria Tironi de Menezes $^{3}$, Caroline Perez Ghirardelli ${ }^{3}$, Adriano Luís \\ Mendonça $^{1}$ e Francisco Chiaravalloti Neto ${ }^{4}$
}

\section{RESUMO}

Introdução: O objetivo deste estudo foi mensurar a diversidade de espécies de culicídeos, descrever sua abundância e variação sazonal em áreas urbanas e matas de São José do Rio Preto, SP, e discutir o risco de ocorrência de arboviroses. Métodos: Coletas de larvas e de mosquitos adultos foram realizadas mensalmente, em 2006 e 2007, em área urbana e em quatro fragmentos de mata. No perímetro urbano, coletaram-se larvas nos sítios mais prováveis de oviposição para mosquitos do gênero Culex e nas matas foi realizada a coleta de mosquitos adultos, sendo que em duas utilizaram-se armadilhas CDC à noite e, em duas, aspirador de Nasci de dia. Resultados: $\mathrm{Na}$ área urbana identificaram-se 34 espécies de culicídeos em um total de 8.683 exemplares; destes, $80,7 \%$ corresponderam ao Culex quinquefasciatus, $9,6 \%$ ao Culex grupo Coronator, $3,2 \%$ ao Aedes albopictus (3,2\%) e 1,1\% ao Ochlerotatusfluviatilis. A abundância de larvas de Cx. quinquefasciatus correlacionou-se negativamente com a chuva. Nas quatro matas, foram coletados 2.268 mosquitos distribuídos entre 10 gêneros, 46 espécies ou grupos. As mais abundantes foram Aedeomyia squamipennis, Culex. coronator, Culex (Mel.) seção Melanoconion, Culex declarator, Ochlerotatus scapularis, Anopheles triannulatus, Culex bidens/interfor e Culex habilitator/pseudojhantinosoma. Conclusões: A abundância de $C x$. quinquefasciatus na área urbana e a presença de outros culicídeos nas áreas urbanas e de matas apontam para a possibilidade de transmissão do vírus do Nilo Ocidental e de outras arboviroses em São José do Rio Preto e outras cidades do Brasil, sendo fundamental o estabelecimento de medidas visando à vigilância destas arboviroses.

Palavras-chaves: Culicidae. Diversidade. Vigilância. Vírus do Nilo Ocidental. Arboviroses.

\begin{abstract}
Introduction: The objectives for this study were to measure the diversity of Culicidae species, describe their abundance and seasonal variation in São José do Rio Preto, SP, and discuss the risk of arbovirus infections. Methods: The collection of larval and adult mosquitoes was conducted monthly from 2006 to 2007 in an urban area and four sections of forested land. In the urban area, larvae were collected from sites where oviposition by Culex mosquitoes was most likely to occur. At two of the four sites in the forested land, adult mosquitoes were collected with the use of CDC traps at night, and a Nasci aspirator was used in the daytime at the two other collection sites. Results: In the urban area, 34 Culicidae species were identified out of a total sample of 8,683 specimens; of these specimens, $80.7 \%$ were Culex quinquefasciatus, $9.6 \%$ were Culex coronator, $3.2 \%$ were Aedes albopictus, and $1.1 \%$ were Ochlerotatus fluviatilis. The abundance of $C x$. quinquefasciatus larvae was negatively related to rainfal. In the woods, 2,268 mosquitoes were collected, representing 10 genera and 46 species. The most abundant mosquito species were Aedeomyia squamipennis, Culex coronator, Culex (Mel.) Melanoconion section, Culex declarator, Ochlerotatus scapularis, Anopheles triannulatus, Culex bidens/interfor and Culex habilitator/pseudojhantinosoma. Conclusions: The abundance of $C x$. quinquefasciatus in the urban area and the presence of other Culicidae species in urban areas and forested land point to the possibility of the transmission of West Nile virus and other arbovirus infections in São José do Rio Preto and other cities. Thus, the enacting of measures aimed at the surveillance of these arbovirus infections is essential.
\end{abstract}

Keywords: Culicidae. Diversity. Surveillance. West Nile vírus. Arbovirus infections.

1. Serviço Regional 8, Superintendência de Controle de Endemias, Governo do Estado de São Paulo, São José do Rio Preto, SP. 2. Laboratório de Vetores, Faculdade de Medicina de São José do Rio Preto, São José do Rio Preto, SP. 3. Laboratório de Entomologia Médica, Superintendência de Controle de Endemias, Governo do Estado de São Paulo, São Paulo, SP. 4. Departamento de Epidemiologia, Faculdade de Saúde Pública, Universidade de São Paulo, São Paulo, SP.

Endereço para correspondência: Dr. Francisco Chiaravalloti Neto. Dept ${ }^{\circ}$ Epidemiologia/FSP/USP. Av. Dr. Arnaldo 715, 01246-904 São Paulo, SP.

Tel: $55113061-7920$

e-mail: franciscochiara@usp.br

Recebido para publicação em 05/12/2009

Aceito em 19/04/2011

\section{INTRODUÇÃO}

O vírus do Nilo Ocidental (VNO) pertence ao gênero Flavivírus e à família Flaviviridae. É transmitido por vetores a aves, equinos e humanos. Neste último, pode causar a febre do Nilo Ocidental, cujos sintomas são febre, dor de cabeça e outros sintomas não específicos ou meningite aguda e encefalite, denominada encefalite do Nilo Ocidental ${ }^{1}$.

As aves são reservatórios naturais do vírus que já foi isolado em mais de setenta espécies e seu comportamento migratório é importante na disseminação do vírus ${ }^{2}$. Equinos também podem se infectar pelo VNO. Estudos sorológicos realizados em aves na Jamaica ${ }^{3}$ e na República Dominicana ${ }^{4}$ detectaram infecção por este vírus no ano de 2002. Neste mesmo ano, pesquisas sorológicas em cavalos e galinhas em Guadeloupe ${ }^{5}$ e em cavalos em Yucatan, Estado do México $^{6}$, constataram infecção pelo VNO. Na França, em 2000, ocorreu uma epidemia de encefalite equina. Três anos depois, o referido vírus foi detectado em seres humanos ${ }^{7}$. No Brasil, no ano de 2003, inquéritos sorológicos foram realizados em aves migratórias e residentes no município de Galinhos/RN $\mathrm{RN}^{8}$ e nos municípios de Mostardas/RS, Tavares/RS e São José do Norte/RS ${ }^{9}$, mas não foi detectada a presença do VNO. Em 2005 anticorpos do VNO foram detectados em cavalos na Colômbia, e em 2006, em cavalos e aves na Venezuela e em cavalos e humanos na Argentina ${ }^{10,11}$.

OVNO foi isolado em 43 espécies de mosquitos dos gêneros Culex, Aedes, Coquillettidia, Anopheles, Mansonia e outros, na Ásia, no Oriente Médio e na Europa, mas principalmente em espécies pertencentes ao gênero Culex ${ }^{12}$. Com a introdução deste vírus nos Estados Unidos, a espécie inicialmente implicada na manutenção do vírus durante o inverno de 1999 e transmissão na região norte foi Culex pipiens. Provavelmente através de aves, o vírus se espalhou para outras áreas, nas quais diferentes espécies de mosquitos estão presentes. $\mathrm{Na}$ região sul dos EUA, Culex quinquefasciatus deve ter garantido o estabelecimento do vírus. Esta espécie de culicídeo veicula o VNO entre aves, algumas das quais migram para a América do Sul no inverno ${ }^{13}$. 
A presença de aves migratórias e culicídeos na área urbana e de matas sinalizam para o risco de introdução e transmissão do VNO e o conhecimento das espécies de mosquitos existentes nestes ambientes propicia subsídios para a vigilância destas enfermidades. Assim, este trabalho visa mensurar a diversidade de espécies de culicídeos, descrever sua abundância e variação sazonal em áreas urbana e de matas no município de São José do Rio Preto (São Paulo, Brasil) e discutir o risco de ocorrência de arboviroses.

\section{MÉTODOS}

São José do Rio Preto localiza-se ao norte do Estado de São Paulo (2049'11" S ; 49²2'46” W) e tinha, em 2006, 415.508 habitantes, dos quais 391.300 encontravam-se na área urbana e 24.208 na área rural. O relevo é pouco ondulado com espigões duplos, a 489 m do nível do mar. A vegetação compreende principalmente cerrado, cerradinho e capoeira, dependendo da fertilidade do solo e abastecimento hídrico. O clima é tropical com inverno seco e ameno (temperatura média do mês mais frio superior a $17^{\circ} \mathrm{C}$ ) e temperatura média anual de $24,92^{\circ} \mathrm{C}$. A precipitação média do mês mais seco é inferior a $60 \mathrm{~mm}$. A região apresenta seis meses chuvosos (outubro a março) e seis meses secos (abril a setembro); a média anual de precipitação é de $1.412 \mathrm{~mm}^{14}$.

As coletas de larvas e adultos de Culicidae foram realizadas com periodicidade mensal (um dia por mês para cada área), de setembro de 2006 a agosto de 2007. A área de estudo para larvas compreendeu a área urbana e para mosquitos, quatro fragmentos de mata estacional semidecídua, três rurais, Mata dos Macacos (2053'01'S, 49024'45”W), mata San Carlo (20042'08”'S, 49020’38”W), mata do Instituto Penal Agrícola (IPA) (2048'36”'S, 49²2'50”W) e um

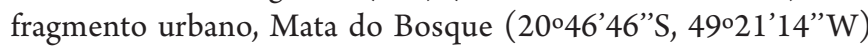
(Figura 1) ${ }^{15,16}$.

No perímetro urbano de São José do Rio Preto foram priorizados os sítios mais prováveis de oviposição para mosquitos do gênero Culex, isto é, criadouros do tipo esgoto, esgoto e vala, esgoto com vala e poça, esgoto e poça, vala e poça ou somente poça, que somados tinham extensão de $15.580 \mathrm{~m}$ (Figura 1). Mensalmente foram sorteados, nesta extensão, 40 pontos e as larvas foram coletadas segundo a técnica de conchadas sistemáticas, sendo que em cada ponto foram realizadas dez conchadas. A concha tinha a capacidade de coletar $625 \mathrm{ml}$ de líquido, totalizando $6.250 \mathrm{ml} \mathrm{em}$ cada ponto amostrado. As larvas foram acondicionadas em frascos contendo álcool 70.

As coletas de mosquitos no interior das matas do IPA e do Bosque foram realizadas com armadilhas CDC durante o período aproximado de $15 \mathrm{~h}$, com início às $17 \mathrm{~h}$ e término às $8 \mathrm{~h}$ do dia seguinte. Em cada mata, foram selecionados cinco pontos equidistantes $100 \mathrm{~m}$ um do outro. No interior das matas San Carlo e dos Macacos as coletas foram realizadas com aspirador de Nasci em torno de quatro pontos equidistantes uns do outros, considerados abrigos para os mosquitos (Figura 1). O aspirador era acionado $15 \mathrm{~min}$ para cada ponto durante o período da manhã, totalizando $1 \mathrm{~h}$ de coleta em cada mata.

As larvas e mosquitos coletados foram encaminhados ao laboratório, onde ocorreu triagem, montagem e identificação até a categoria de espécie. As chaves taxonômicas contidas em Forattini ${ }^{17}$ e Sirivanakarn ${ }^{18}$ foram utilizadas nas identificações. As abreviações dos gêneros das espécies de mosquitos foram feitas de acordo com Reinert ${ }^{19}$.

As informações diárias sobre chuva e temperatura foram obtidas no Escritório de Desenvolvimento Rural de São José do Rio Preto.

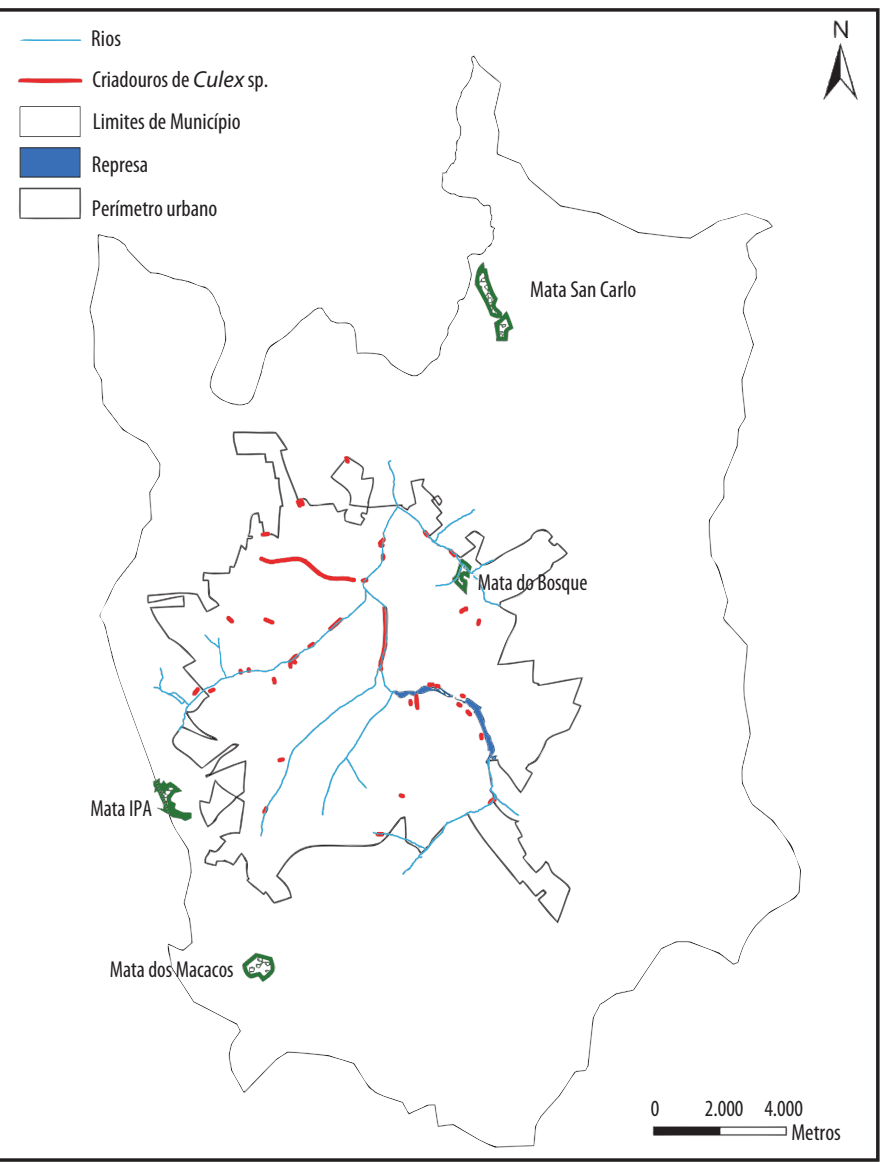

FIGURA 1 - Mapa do município de São José do Rio Preto destacando os sítios mais prováveis de oviposição onde foram realizadas as coletas de larvas de culicídeos na área urbana e os fragmentos de mata em que se coletaram exemplares adultos. IPA: Instituto Penal Agrícola

Os dados das identificações de mosquitos, registrados em boletins específicos, e os pluviométricos foram digitados no programa Microsoft Excel. As tabulações, gráficos e cálculos estatísticos foram realizados no Excel, SPSS para Windows versão 13.0 e Bioestat versão 4.0 .

Na mensuração da diversidade de larvas e mosquitos adultos foram utilizados os índices de dominância (Is) e diversidade (Ds) de Simpson. A diversidade, dominância e riqueza dos mosquitos foram analisadas comparando-se as áreas de mata duas a duas de acordo com a técnica de coleta utilizada. Utilizou-se o índice de Margalef $\left(D_{m g}\right)$ para estimar a diversidade enfatizando a riqueza de espécies ${ }^{20}$. Os valores obtidos pelo cálculo do índice de diversidade de Simpson $\left(\mathrm{D}_{\mathrm{S}}\right)$ foram comparados quanto à significância pelo teste-t de Hutcheson ${ }^{21}$. Para a descrição da similaridade de espécies entre os habitats de mata, respeitando as técnicas de coleta, foram utilizados os índices de similaridade de Sorensen quantitativo $\left(\mathrm{I}_{\mathrm{S} \text { quant. }}\right)$ e qualitativo $\left(\mathrm{I}_{\mathrm{S} \text { qual. }}\right)^{20}$.

A normalidade das distribuições dos dados entre as variáveis e homocedasticidade de variâncias foram verificadas respectivamente por meio dos testes de Kolmogorov-Srminoff, Shapiro-Wilke Levene. Como não foram observadas tais condições entre as variáveis de estudo fez-se a opção pelos testes não-paramétricos. $\mathrm{O}$ teste não paramétrico de Mann-Whitney foi utilizado para verificar a diferença entre os valores das abundâncias numéricas, para cada uma das espécies de mosquitos dominantes, entre os períodos seco e chuvoso. Em cada um dos dois períodos considerados, o teste de Friedman foi 
utilizado para verificar a diferença entre os valores das abundâncias numéricas das quatro espécies de mosquitos dominantes, analisadas duas a duas. Para ambos os testes o nível de significância foi de 0,05.

As informações de coletas de mosquitos, por data, foram associadas com a chuva acumulada e a média das temperaturas médias de 10 dias anteriores, sendo utilizada a correlação de Spearman para verificar a existência de correlação entre estas variáveis.

\section{RESULTADOS}

Na Tabela 1, constam as espécies de larvas de culicídeos coletadas na área urbana do município de São José do Rio Preto, segundo período chuvoso e seco e total obtido. Identificaram-se 34 espécies de culicídeos em um total de 8.683 exemplares. Destes, 7.008 (80,7\%) corresponderam à espécie Culex quinquefasciatus, 837 (9,6\%) ao

TABELA 1 - Distribuição de espécies de larvas de Culicídeos coletadas na área urbana do município de São José do Rio Preto, segundo períodos chuvoso e seco, de setembro de 2006 a agosto de 2007.

\begin{tabular}{|c|c|c|c|}
\hline \multirow[b]{2}{*}{ Espécies ou grupos taxonômicos } & \multicolumn{3}{|c|}{ Período } \\
\hline & chuvoso & seco & total \\
\hline Aedes aegypti & 18 & - & 18 \\
\hline Aedes albopictus & 197 & 78 & 275 \\
\hline Anopheles (Nys.) sp & 1 & 21 & 22 \\
\hline Anopheles albitarsis & - & 1 & 1 \\
\hline Anopheles albitarsis /marajoara & - & 1 & 1 \\
\hline Anopheles argyritarsis argyritarsis & 15 & 39 & 54 \\
\hline Anopheles argyritarsis argyritarsis aff. & - & 1 & 1 \\
\hline Anopheles argyritarsis sawyeri & - & 5 & 5 \\
\hline Anopheles argyritarsis sawyeri aff. & - & 1 & 1 \\
\hline Anopheles brasiliensis/anomophylus & - & 1 & 1 \\
\hline Anopheles (Sth.) kompi aff. & 1 & 1 & 2 \\
\hline Anopheles oswaldoi & - & 1 & 1 \\
\hline Anopheles strodei & - & 1 & 1 \\
\hline Anopheles strodei/evansae & - & 1 & 1 \\
\hline Anopheles strodei/rondoni & - & 1 & 1 \\
\hline Anopheles triannulatus & - & 48 & 48 \\
\hline Anopheles triannulatus/davisi & - & 1 & 1 \\
\hline Culex (Cux.) sp & 1 & - & 1 \\
\hline Culex chidesteri & 56 & 22 & 78 \\
\hline Culex corniger & 34 & - & 34 \\
\hline Culex grupo coronator & 439 & 398 & 837 \\
\hline Culex mollis & 22 & - & 22 \\
\hline Culex nigripalpus & - & 57 & 57 \\
\hline Culex quinquefasciatus & 1.519 & 5.489 & 7.008 \\
\hline Culex tarsalis & - & 22 & 22 \\
\hline Culex triambus/mollis & 19 & - & 19 \\
\hline Limatus sp & 38 & - & 38 \\
\hline Limatus durhamii & 6 & - & 6 \\
\hline Ochlerotatus fluviatilis & 9 & 84 & 93 \\
\hline Ochlerotatus scapularis & 2 & 7 & 9 \\
\hline Psorophora ciliata & 4 & - & 4 \\
\hline Psorophora cingulata & 1 & - & 1 \\
\hline Psorophora discrucians & 6 & - & 6 \\
\hline Psorophora varipes/albigenu & 14 & - & 14 \\
\hline Total & 2.402 & 6.281 & 8.683 \\
\hline
\end{tabular}

Culex grupo Coronator, 275 (3,2\%) Aedes albopictus e 93 (1,1\%) Ochlerotatus fluviatilis.

O índice de diversidade para a área urbana foi de Ds $=0,33$ e o índice de dominância de Simpson, Is = 0,67. Com relação à riqueza, nota-se que 20 espécies ou grupos ocorreram no período chuvoso e 23 espécies ou grupos ocorreram no período seco. Este último também apresentou maior quantidade de exemplares coletados $(72,3 \%)$ que o chuvoso (27,7\%). A espécie $C x$. quinquefasciatus contribuiu com 1.519 exemplares no período chuvoso, que correspondeu a $63,2 \%$ das larvas coletadas neste período, seguida por $C x$. grupo Coronator com 439 (18,3\%), Ae. albopictus com 197 (8,2\%) e Oc.fluviatilis com 9 (0,4\%). Culex quinquefasciatus contribuiu com 5.489 exemplares no período seco, que correspondeu a $87,4 \%$ das larvas coletadas neste período, seguido por $C x$. grupo Coronator com 398 (6,3\%), Ae. albopictus com 78 (1,2\%) exemplares e Oc. fluviatilis com 84 (1,3\%) (Tabela 1).

Um ponto de coleta, no período seco, onde foram coletadas 2.380 larvas (maio/2007), foi considerado out lier e retirado da análise. As comparações entre as abundâncias numéricas das quatro espécies dominantes de larvas em criadouros da área urbana do município de São José do Rio Preto ( $C x$. quinquefasciatus, $C x$. grupo Coronator, Ae. albopictus e Oc. Fluviatilis), entre os períodos chuvoso e seco, mostraram que apenas $C x$. quinquefasciatus apresentou diferença entre os dois períodos no teste de Mann-Whitney $(\mathrm{p}<0,0024)$ sendo maior no período seco. Neste período, $C x$. quinquefasciatus foi mais abundante que $C x$. grupo Coronator, Ae. albopictus e Oc. fluviatilis; Cx. grupo Coronator foi mais abundante que Ae. albopictus e Oc.fluviatilis, todos com $\mathrm{p}<0,0001$ no teste de Friedman e Ae. albopictus e Oc. fluviatilis não apresentaram diferença significante. No período chuvoso, $C x$. quinquefasciatus foi mais abundante que Cx. grupo Coronator, Ae. albopictus e Oc. fluviatilis, todos com $\mathrm{p}<0,0001$ no teste de Friedman e estes três não apresentaram diferença significante quando comparados entre si.

Verificou-se, por meio da utilização do coeficiente de correlação de Sperman $\left(\mathrm{r}_{\mathrm{s}}\right)$, que a abundância de larvas de Cx. quinquefasciatus apresentou correlação negativa e significante com a chuva acumulada $\left(r_{s}=-0,1997 ; \mathrm{p}=0,000\right)$ e que a abundância de Ae. albopictus apresentou correlações positivas e significantes com a chuva acumulada $\left(r_{s}=0,1147 ; \mathrm{p}=0,0124\right)$ e com a temperatura média $\left(r_{s}=0,1142\right.$; $\mathrm{p}=0,0120)$. A abundância numérica de larvas de $C x$. quinquefasciatus não apresentou correlação significante com a temperatura e as abundâncias de $C x$. grupo Coronator e $O c$. fluviatilis não apresentaram correlação significante com a chuva acumulada e a temperatura.

A composição das espécies ou grupos de mosquitos coletadas nos quatro fragmentos de mata estudados para o município de São José do Rio Preto pode ser vista na Tabela 2. No total, foram coletados 2.268 mosquitos distribuídos entre 10 gêneros, 46 espécies ou grupos. $\mathrm{O}$ habitat com maior número de exemplares foi o da mata do Instituto Penal Agrícola (IPA) 970 (42,7\%) em relação ao total de mosquitos coletados, seguido da mata dos Macacos 673 (29,7\%), mata San Carlo 388 (17,1\%), na área rural e mata do Bosque 237 (10,4\%), na área urbana. Na mata do IPA registraram-se 29 espécies contra 21 nos habitats de mata do Bosque e mata dos Macacos. A menor riqueza, 16 espécies, foi registrada para a mata San Carlo.

Os mosquitos das espécies Aedeomyia squamipennis com 470 (48,4\%), Cx. (Mel.) seção Melanoconion com 170 (17,5\%), Anopheles triannulatus $77(7,9 \%)$ e Uranotaenia pulcherrima com 41 (4,2\%) exemplares, foram os mais abundantes na mata do IPA, em relação ao total coletado naquele habitat. A Figura $2 \mathbf{A}$ apresenta 
TABELA 2 - Abundância numérica das espécies ou grupos de mosquitos coletados em quatro fragmentos de mata do município de São José do Rio Preto.

\begin{tabular}{|c|c|c|c|c|c|}
\hline \multirow[b]{2}{*}{ Espécies ou grupos taxonômicos } & \multicolumn{5}{|c|}{ Mata } \\
\hline & Bosque & San Carlo & Macacos & IPA & Total \\
\hline Aedeomyia squamipennis & 1 & - & - & 470 & 471 \\
\hline Aedes albopictus & 2 & 5 & 1 & - & 8 \\
\hline Anopheles albitarsis s.l & - & - & - & 11 & 11 \\
\hline Anopheles argyritarsis & - & - & - & 6 & 6 \\
\hline Anopheles benarrochi & 3 & - & - & 5 & 8 \\
\hline Anopheles darlingi & - & - & - & 2 & 2 \\
\hline Anopheles evansae & 2 & - & 1 & 3 & 6 \\
\hline Anopheles galvaoi & - & - & - & 2 & 2 \\
\hline Anopheles parvus & - & - & - & 5 & 5 \\
\hline Anopheles strodei & 2 & - & - & - & 2 \\
\hline Anopheles triannulatus & - & - & - & 77 & 77 \\
\hline Coquillettidia venezuelensis & 2 & - & 1 & 6 & 9 \\
\hline Culex grupo Coronator & 45 & 55 & 251 & 19 & 370 \\
\hline Culex declarator & 58 & 98 & 145 & 7 & 308 \\
\hline Culex dolosus & - & - & - & 28 & 28 \\
\hline Culex mollis & - & - & 1 & - & 1 \\
\hline Culex nigripalpus & - & 1 & - & - & 1 \\
\hline Culex quinquefasciatus & 5 & - & - & - & 5 \\
\hline Culex saltanensis & 4 & - & 2 & - & 6 \\
\hline Culex scimitar & 9 & 14 & 29 & 9 & 61 \\
\hline Culex leviscastilloi & 4 & 4 & 34 & - & 42 \\
\hline Culex bidens/interfor & 8 & 68 & 64 & 19 & 159 \\
\hline Culex mauensensis & - & - & 1 & - & 1 \\
\hline Culex ameliae & - & 1 & 2 & 5 & 8 \\
\hline Culex habilitator/pseudojhantinosoma & 54 & 34 & 36 & - & 124 \\
\hline Culex (Mel.)Seção Spissipes & - & 4 & 1 & 2 & 7 \\
\hline Culex (Mel.)Seção Melanoconion & 4 & 6 & 3 & 170 & 183 \\
\hline Culex & - & - & - & 3 & 3 \\
\hline \multicolumn{6}{|l|}{ (Mel.)Sec.Mel.gr.Distenguendus } \\
\hline Culex (Mel.)Sec.Mel.gr.Erraticus & 2 & - & 1 & 7 & 10 \\
\hline Culex (Mel.)Sec.Mel.gr.Intrincatus & 4 & - & - & - & 4 \\
\hline Culex (Mel.)idottus & 5 & - & - & 2 & 7 \\
\hline Culex (Mel.)Sec.Mel.gr.Atratus & - & - & - & 5 & 5 \\
\hline Haemagogus (Con.)leucocelaenus & - & - & 10 & - & 10 \\
\hline Mansonia flaveola & 4 & - & - & - & 4 \\
\hline Mansonia humeralis & - & - & - & 28 & 28 \\
\hline Mansonia wilsoni & - & 1 & - & - & 1 \\
\hline Mansonia titillans & - & - & - & 5 & 5 \\
\hline Ochlerotatus scapularis & 18 & 90 & 59 & 2 & 169 \\
\hline Ochlerotatus serratus & - & - & 3 & - & 3 \\
\hline Ochlerotatus terrens & - & 1 & 16 & - & 17 \\
\hline Psrophora ferox/pseudomelanota & 1 & 5 & 12 & - & 18 \\
\hline Uranotaenia apicalis & - & - & - & 2 & 2 \\
\hline Uranotaenia geometrica & - & - & - & 3 & 3 \\
\hline Uranotaenia lowi & - & 1 & - & - & 1 \\
\hline Uranotaenia nataliae & - & - & - & 25 & 25 \\
\hline Uranotaenia pulcherrima & - & - & - & 42 & 42 \\
\hline Total & 237 & 388 & 673 & 970 & 2.268 \\
\hline
\end{tabular}

a distribuição destas espécies nos períodos seco e chuvoso. As abundâncias para as espécies entre si não apresentaram diferença significante no período seco. No período de chuvas, apenas a abundância de Ad. squamipennis foi equivalente às abundâncias de An. triannulatus e Ur. pulcherrima (teste de Friedman, $\mathrm{p}<0,05)$. Na comparação das abundâncias de cada uma das espécies entre os períodos seco e chuvoso nenhuma delas apresentou diferença significante.

Na mata do Bosque registrou-se baixa abundância para as espécies de mosquitos. $\mathrm{Na}$ tribo Culicini as espécies $C x$. declarator com 58 (24,5\%) exemplares, Culexhabilitator/pseudojanthinosoma com 54 (22,8\%), Cx. coronator com 45 (19\%) e Oc. scapularis com $18(7,6 \%)$ exemplaresforamàs espécies mais abundantes comparado ao total coletado para aquele habitat. As abundâncias das quatro espécies não apresentaram diferenças significantes quando comparadas nos períodos seco e chuvoso. Também não apresentaram diferenças significantes quando comparadas entre si dentro de cada um dos períodos (Figura 2B).

Na mata dos Macacos, os mosquitos da tribo Culicini foram dominantes. Em relação às outras espécies ou grupos, destacam-se Culex coronator com 251 (37,3\%) seguido de Culex declarator com 145 (21,5\%) e Culex bidens/interfor com 64 (9,5\%) e Ochlerotatus scapularis com 59 (8,8\%) exemplares em relação ao total no habitat. A distribuição destas espécies, segundo períodos seco e chuvoso é apresentada na Figura 3A. As abundâncias destas quatro espécies não apresentaram diferenças significantes entre si no período seco.Já no período de chuvas, a diferença entre as abundâncias foi significante (teste de Friedman, $\mathrm{p}<0,05)$. Na comparação entre os períodos de seca e de chuva, as abundâncias de $C x$. coronator e $O c$. scapularis foram significativamente maiores no período chuvoso do que no seco, com valores de $\mathrm{p}$ respectivamente iguais a 0,0001 e 0,0076 para as espécies no teste de Mann-Whitney.

Na mata San Carlo, os mosquitos das tribos Aedini e Culicini foram dominantes. As espécies mais abundantes foram $C x$. declarator 98 (25,3\%) exemplares, Oc. scapularis com 90 (23,2\%), Cx. bidens/interfor com $68(17,5 \%)$ e Cx. coronator com 55 (14,2\%). As abundâncias das quatro espécies não apresentaram diferenças significantes quando comparadas entre si, tanto no período seco como no chuvoso (Figura 3B). A espécie $C x$. coronator foi mais abundante no período chuvoso do que no seco (teste de Mann-Whitney, $\mathrm{p}=0,0412$ ), o mesmo ocorreu para o Oc. scapularis ( $\mathrm{p}=0,0023)$.

Os resultados mostraram que a diversidade de Simpson $\left(D_{S}\right)$ para os mosquitos coletados na mata San Carlo $\left(D_{s}=0,81\right)$ foi maior quando se comparou à mata dos Macacos $\left(D_{S}=0,79\right)$. Essa diferença foi pouco significante com $(\mathrm{p}<0,05)$, com tobservado $=2,07, \mathrm{t}$ crítico $0,05(2) 1042=1,96$. O valor de $\mathrm{p}$ esteve entre 0,05 e 0,025 . A dominância de espécies foi 


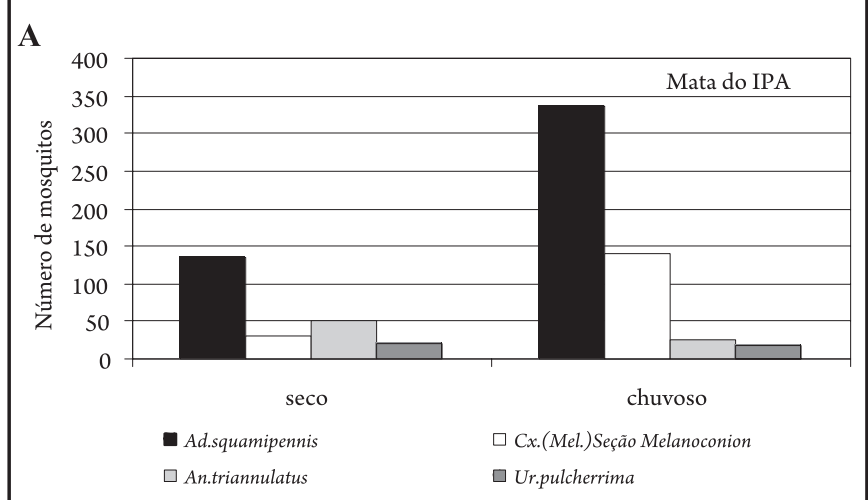

B

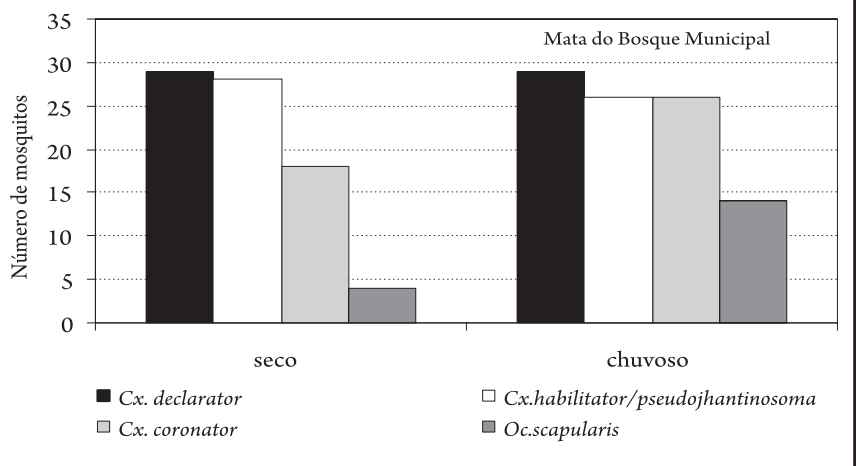

FIGURA 2 - Distribuição nos períodos chuvoso e seco do número das espécies de mosquitos mais abundantes coletados com armadilhas CDC na mata do Instituto Penal Agrícola (IPA) (A) e na mata do Bosque (B), município de São José do Rio Preto, no período de setembro de 2006 a agosto de 2007.

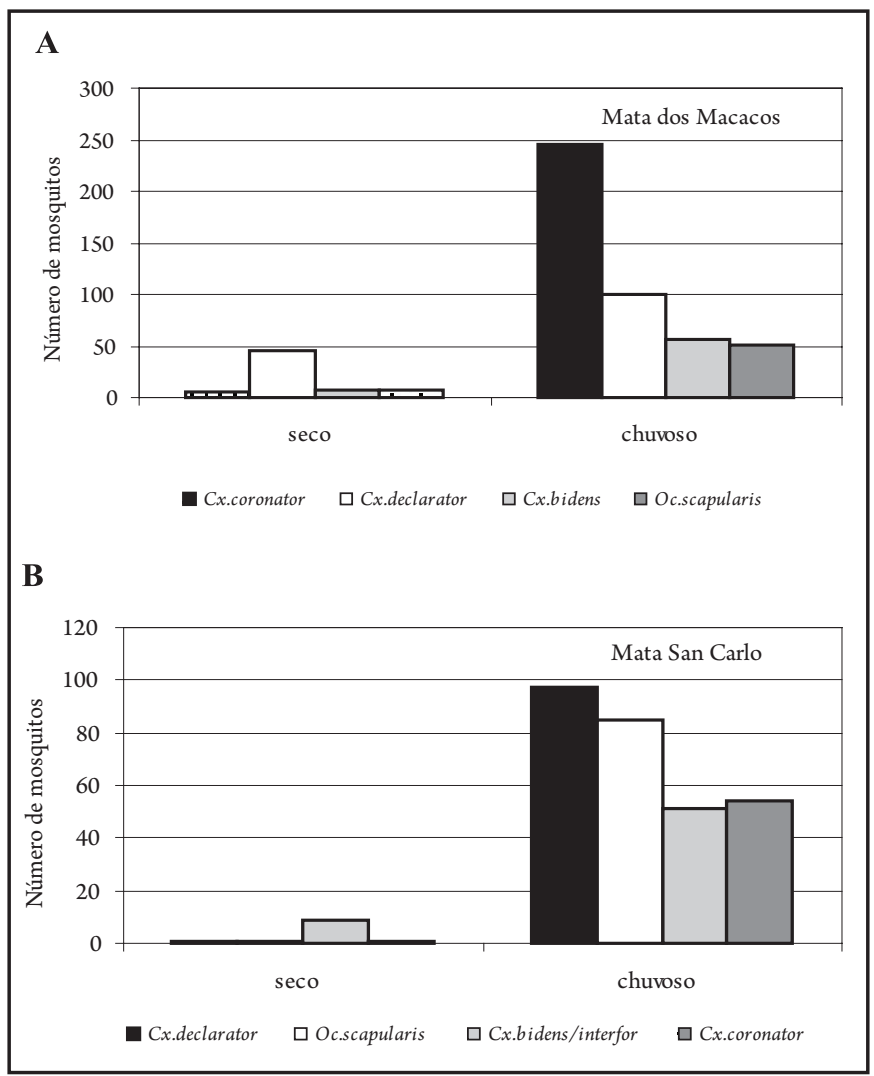

FIGURA 3 - Distribuição nos períodos chuvoso e seco do número das espécies de mosquitos mais abundantes coletados com aspirador de Nasci na mata dos Macacos (A) e na mata San Carlo (B), município de São José do Rio Preto, no período de setembro de 2006 a agosto de 2007. maior na mata dos Macacos $\left(\mathrm{I}_{\mathrm{S}}=0,21\right)$, comparada à mata San Carlo $\left(\mathrm{I}_{\mathrm{S}}=0,18\right)$. O cálculo da diversidade enfatizando a riqueza mostrou que a mata dos Macacos $\left(D_{m g}\right)=2,61$ é mais rica em termos de diversidade de espécies comparado à mata San Carlo $\left(\mathrm{D}_{\mathrm{mg}}=2,190\right)$.

A estimativa do índice de dominância de Simpson $\left(\mathrm{I}_{\mathrm{S}}\right)$ mostrou que a dominância das espécies de mosquitos na mata do IPA $\left(\mathrm{I}_{\mathrm{S}}=0,38\right)$ foi maior comparado à mata do Bosque $\left(\mathrm{I}_{\mathrm{S}}=0,16\right)$, resultando em uma diversidade de Simpson maior para a mata do Bosque $\left(D_{S}=0,83\right)$ quando comparado à mata do IPA $(\mathrm{Ds}=0,62)$. Esses resultados foram significantes no nível de $0,05 \mathrm{com}$ $\mathrm{t}_{\text {observado }}=9,02, \mathrm{t}_{\text {crítico (2)986,8 }}=1,96$ essa diferença foi muito significante $(\mathrm{p}<0,001)$. A riqueza de espécies foi maior para a mata do IPA $\left(\mathrm{D}_{\mathrm{mg}}\right)=3,45$ quando comparada à mata do Bosque $\left(\mathrm{D}_{\mathrm{mg}}\right)=3,13$.

Quanto à similaridade de espécies, pode-se observar que a mata dos Macacos quando comparada à mata San Carlo apresentase mais similar $\left(I_{S \text { quant. }}=0,62\right)$ quantitativa e qualitativamente $\left(\mathrm{I}_{\mathrm{S}_{\text {qual. }}}=0,69\right)$ do que a comparação mata do IPA e mata do Bosque $\left(\mathrm{I}_{\mathrm{S} \text { quant. }}=0,11 \mathrm{e} \mathrm{I}_{\mathrm{S} \text { qual. }}=0,48\right)$.

Com relação às associações entre o número de exemplares das espécies mais abundantes coletadas nos fragmentos de matas e dados climáticos, An. triannulatus coletado na mata do IPA registrou correlação positiva $\left(\mathrm{r}_{\mathrm{s}}=0,72 ; \mathrm{p}=0,0087\right)$ com a temperatura média; os números de exemplares das espécies $C x$. declarator $\left(\mathrm{r}_{\mathrm{s}}=0,67\right.$; $\mathrm{p}=0,0174), C x$. bidens/interfor $\left(\mathrm{r}_{\mathrm{s}}=0,67 ; \mathrm{p}=0,0167\right)$ e Oc. scapularis $\left(\mathrm{r}_{\mathrm{s}}=0,72 ; \mathrm{p}=0,0084\right)$ coletados na mata San Carlo, também apresentaram correlação positiva com a temperatura média. Verificou-se correlação positiva entre o número de exemplares de Oc. scapularis $\left(r_{s}=0,59 ; \mathrm{p}=0,0444\right)$ e Cx. coronator $\left(r_{s}=0,62\right.$; $\mathrm{p}=0,0314)$ coletados na mata San Carlo e a chuva acumulada.

\section{DISCUSSÃo}

A riqueza de espécies de mosquitos, principalmente as das tribos Culicini e Aedini, coletadas nas áreas urbanas e de matas da Cidade de São José do Rio Preto, chama a atenção pela grande importância epidemiológica de algumas delas na transmissão de arboviroses.

A elevada abundância e proliferação de $C x$. quinquefasciatus ao longo do ano estão relacionadas com as condições ecológicas presentes na área urbana do município de São José do Rio Preto: a presença de criadouros formados pelas margens de córregos e esgotos a céu aberto; a elevada densidade da população humana servindo de fonte sanguínea e de domicílios de abrigo; a presença de aves também servindo como fonte de alimento para essa espécie de mosquito de conhecida antropofília e ornitofilia.

Estudos de competência vetorial realizado na Califórnia demonstraram que $C x$. quinquefasciatus é vetor eficiente em laboratório e na natureza, podendo transferir o VNO de aves para humanos e cavalos ${ }^{22}$. Outros estudos mostraram sua competência vetorial para transmitir arbovírus da família flaviviridae como o vírus das encefalites de Saint Louis (SLEV) nos Estados Unidos, principalmente na parte leste, e o VNO na Europa ${ }^{12}$ e América do Norte ${ }^{13,17,23,24}$.

A ocorrência de aves migratórias em São José do Rio Preto e em outros centros urbanos do Estado de São Paulo e Brasil é um elemento importante a ser considerado. Entre elas podem ser citadas a andorinha (Hirundo rústica), comum nos habitats de brejos, banhados, lagos e áreas antropizadas; o falcão (Falco peregrinus), 
de áreas antropizadas; e o gavião (Buteo swaisoni) de mata mesófilo semidecídua, aves que migram para a América latina, com anticorpos contra VNO e/ou RNA viral de VNO. O pardal (Passer domesticus) de áreas antropizadas, competente para transmitir $\mathrm{VNO}$ e registrado no Estado de São Paulo, poderia ter o papel de hospedeiro amplificador do $\mathrm{VNO}^{2}$ (Araújo FAA: Comunicação Pessoal, 2007).

Essas condições em conjunto apontam para o possível e/ou futuro papel do $C x$. quinquefasciatus na transmissão do VNO, do SLEV e de outras arboviroses no município de São José do Rio Preto e em áreas urbanas com condições semelhantes. Também deve ser citado o risco de ocorrência de filariose bancroftiana, que ainda persiste em focos residuais de cidades das regiões nordeste do país ${ }^{25}$. Estas hipóteses foram fortalecidas pela identificação de um surto de encefalite pelo SLEV em São José do Rio Preto em $2007^{26}$.

A elevada abundância no período de seca e a relação inversa com a chuva confirmam o comportamento por diversas vezes relatado das formas imaturas de Cx.quinquefasciatus que se desenvolvem em criadouros altamente poluídos com condições anoréxicas, acrescidos de contaminantes e praticamente livres de predadores. A chuva deve controlar essa população de mosquitos, quando altera as condições físico-químicas nos criadouros ou mesmo carreia larvas, pupas e jangadas de ovos de um ponto do criadouro para outro, nos córregos ${ }^{27,28}$. Os $C x$. quinquefasciatus adultos resultantes, principalmente da grande proliferação no período seco, invadem os domicílios causando incômodo e colocam a população em risco de infecção pelas doenças citadas. O bom gerenciamento dos efluentes líquidos, domésticos ou industriais minimizaria esse grave problema de saúde pública na área urbana do município de São José do Rio Preto, bem como em outros centros urbanos do Estado de São Paulo e do Brasil.

Estudos realizados na Cidade de São Paulo, um dos maiores centros urbanos mundiais, também revelaram a presença desse vetor. Urbinatti $\operatorname{cols}^{29}$, em estudo de composição e frequência de formas imaturas de culicídeos no Parque Ecológico do Tietê, São Paulo, verificaram que $C x$. quinquefasciatus foi a espécie mais abundante e única nas coletas realizadas em um canal artificial que recebia efluentes domésticos em área de ocupação irregular. Morais cols ${ }^{30}$, em estudo da distribuição da frequência do vetor no rio Pinheiros, São Paulo, mostraram que a espécie foi exclusiva, na margem do rio, e que nos picos de estiagem a frequência foi semelhante ao longo de toda extensão do rio.

A presença, praticamente com a mesma abundância, tanto no período seco como no chuvoso de larvas de $C x$. grupo Coronator, o segundo mais abundante coletado na área urbana de São José do Rio Preto, pode ser devida ao fato de que as formas imaturas desse mosquito são ecléticas quanto ao criadouro de solo que podem ser temporários, como as poças d'água, ou perenes, como as margens dos grandes criadouros nos rios, represas ou mesmo córregos ${ }^{17}$. Os baixos valores de abundância da espécie $C x$. coronator na forma adulta, nas quatro áreas de mata, em relação à registrada na área urbana, estão relacionados, muito provavelmente, com a maior oferta de criadouros nesta área.

Nas matas dos Macacos e San Carlo, a espécie Cx. coronator foi registrada em maior abundância comparada às outras espécies distribuídas para aqueles habitats. A ocorrência da espécie, sempre em maior abundância durante o período chuvoso, nestas duas matas, evidencia que as fêmeas ovipõem em criadouros de solo formados pelas águas da chuva acumulada, visto que não se observou a presença de criadouros de grande porte como os remansos de rios, lagos ou represas que pudessem representar criadouros para a espécie. Até o momento, a espécie $C x$. coronator, não foi incriminada como vetor do $\mathrm{VNO}$, mas pode atuar como um elo entre as aves migratórias, aves nativas e o homem, facilitando a transmissão de arbovírus, como o Mucambo ou SLEV ${ }^{17,31}$.

A maior abundância da espécie Ae. albopictus no período de chuvas na área urbana está de acordo com a sua dependência da precipitação para a formação de seus criadouros ${ }^{27,32}$ e são concordantes com os resultados encontrados por Serpa cols ${ }^{33}$. Em condições de laboratório, Ae. albopictus é um vetor eficiente do $\mathrm{VNO}^{34}$ e de febre amarela ${ }^{17}$ e poderia atuar como um vetor ponte destes vírus na natureza ${ }^{35,36}$. Gomes $\operatorname{cols}^{37}$ constataram que a infestação por $A e$. albopictus no Brasil ocorre na direção dos focos de febre amarela silvestre, o que indica que esta espécie poderá vir a atuar como elo entre os ambientes urbano e rural, na transmissão do vírus. Como exemplo desta situação, podemos citar a própria região cuja sede é São José do Rio Preto, que tem suas áreas urbanas e rurais infestadas pelo vetor. Nela ocorreram dois óbitos por febre amarela silvestre em $2000^{38}$ e, em 2008, o vírus foi isolado em quatro macacos ${ }^{39}$.

Aedes albopictus é vetor primário do vírus do dengue em áreas rurais da Ásia e do vírus da encefalite japonesa no mesmo continente. Foram registrados isolamentos do vírus do dengue tipo 1 de pools de larvas coletadas no Estado de Minas Gerais (Brasil) e dos vírus Potosi e encefalite equina do leste na América do Norte ${ }^{17,40}$.

Para o Oc.fluviatilis, quarta espécie mais abundante na área urbana e sem ocorrência nas áreas de mata, existe a hipótese, não confirmada, da atuação na transmissão do vírus da febre amarela na natureza; sua eficácia é pequena na transmissão de dirofilariose canina e infecta-se com plamódios aviários em laboratório ${ }^{17,41}$.

Nos parágrafos seguintes, é feita a comparação entre as espécies mais abundantes registradas nas áreas de mata, respeitando-se os diferentes esforços de coleta utilizados. Acredita-se que a presença de $C x$. declarator, $C x$. coronator e $C x$. bidens em maior abundância na mata dos Macacos conferiram uma maior dominância de Simpson para o habitat comparado à mata San Carlo, que apresentou maior diversidade de Simpson provavelmente devido à maior equitabilidade do número de exemplares distribuídos pelas espécies e com certeza pela maior riqueza registrada para a mata dos Macacos.

As maiores abundâncias verificadas, para as espécies de mosquitos dos gêneros Culex e Ochlerotatus, a exemplo de $C x$. declarator e Cx. coronator, e Oc. scapularis para a mata San Carlo e mata dos Macacos, mostram que, muito provavelmente essas fêmeas criam-se em criadouros que sofrem a influência direta das chuvas para mantê-los, visto que se observou tratarem-se de matas secas, sem a presença de grandes criadouros, embora não tenha ocorrido correlação significante entre a abundância numérica dessas espécies e a variável chuva acumulada.

Os bebedouros ou outras pequenas coleções aquáticas de solo, intermitentes, recipientes naturais ou artificiais ${ }^{17,27}$ presentes no interior do zoológico do Bosque poderiam também manter as espécies $C x$. bidens/interfor, $C x$. declarator $\mathrm{C} x$. coronator, contudo neste habitat também não se observou correlação da chuva com as espécies mais abundantes. A baixa abundância numérica registrada para estas espécies pode ter influenciado diretamente o cálculo do índice de diversidade de Simpson que se tornou maior para esse habitat, comparado à mata do IPA que apresentou uma maior riqueza de espécies, contra uma menor riqueza comparada a mata do Bosque que registrou além da baixa abundância, maior equitabilidade entre as espécies. 
As fêmeas de $C x$. declarator, $C x$. bidens/interfor e $C x$. habilitator/ pseudojanthinosoma não estão relacionadas com a febre do Nilo Ocidental até o momento, contudo, $C x$. coronator, $C x$. declarator e Cx. habilitator/pseudojanthinosoma podem exercer a hematofagia em aves ou em humanos, atuando no ciclo de transmissão de arbovírus entre aquelas ou das aves para os seres humanos ${ }^{17}$. Culex bidens/ interfor também pode atuar na transmissão do vírus da encefalite equina leste no norte da Argentina de acordo com Forattini ${ }^{17}$. Já Oc. scapularis podem veicular encefalite do Rocio, e foram isolados dessa espécie os vírus da encefalite equina venezuelana e Ilhéus ${ }^{17,27,42}$. Durante a estação climática em que essas espécies ocorrerem em maior abundância, a população humana que adentre a essas áreas de mata estará sujeita a um maior contato com esses mosquitos que podem veicular agentes de doenças como os arbovírus.

A maior riqueza de espécies verificada pelo registro do próprio número de espécies e pela mensuração do índice de Margalef $\left(\mathrm{D}_{\mathrm{mg}}\right)$ para a mata do IPA confirma que se trata de uma área mais conservada quando comparada à mata do Bosque, que está ladeada pelo ambiente urbano. A maior dominância de espécies para aquele habitat pode ser devido ao grande criadouro, uma lagoa, a beira da mata que produz mosquitos durante o ano todo e aparentemente sofre pouca ou nenhuma influência direta das chuvas. Uma evidência disso é que não se observou correlação entre as espécies mais abundantes: Ad. squamipennis, An. triannulatus e Cx. (Mel.) seção Melanoconion e os valores de precipitação pluviométrica.

Aedeomyia squamipennis foi encontrado com o vírus da encefalite equina venezuelana (EEV), no norte da Argentina. É considerado vetor do vírus Gamboa e do parasita da malária em aves na Venezuela ${ }^{17,43,44}$. O subgênero Melanoconium também pode atuar na transmissão de arbovírus, como o da $\mathrm{EEV}^{17}$.

Outras espécies com menor número de exemplares coletados, porém importantes vetores de arbovírus merecem ser mencionadas. Haemagogus leucocelaenus podem atuar na transmissão do vírus da febre amarela silvestre entre os macacos. Culex nigripalpus, Culex tarsalis e Psorophora ciliata, já foram incriminadas por Granwehr $\mathrm{cols}^{13}$ como vetores do VNO na América do Norte. Aedes aegypti muito pesquisado e monitorado na região de São José do Rio Preto, transmite os sorotipos virais que causam a forma clássica ou hemorrágica do dengue, um dos maiores problemas de saúde pública mundial e é vetor do vírus da febre amarela urbana ${ }^{45}$. Culex tarsalis, presente na área urbana, e aves passeriformes participam na amplificação primaveril do ciclo de transmissão de encefalite equina oeste, na América do Norte. Nos Estados Unidos é reconhecido como vetor da SLEV, sendo que esta espécie tem grande potencial para amplificar e manter o VNO na Califórnia ${ }^{22}$. Psorophora ferox/ pseudomelanota apresenta potencial para a transmissão do VNO, segundo Granwehr cols ${ }^{13}$.

As espécies de culicídeos encontradas nas áreas urbana e de mata de São José do Rio Preto colocam o município sob risco de ocorrência de arboviroses, com destaque para a transmissão do VNO em função da grande abundância de $C x$. quinquefasciatus. A mesma realidade deve estar presente em uma série de cidades médias e grandes do Brasil, com problemas semelhantes de infestação pelo vetor decorrentes de inadequada infra-estrutura de saneamento ${ }^{46}$. Diante deste quadro, é fundamental o estabelecimento de medidas visando à vigilância desta como de outras arboviroses.

\section{AGRADECIMENTOS}

Os autores agradecem Ana Patrícia Chierotti, Antônio Nunes Basto, Beatriz Aparecida Coelho Belini, José Luis de Souza, Mariana Ferrari Silveira, Neuza F. A. Santana e Perpétua M. M. Sereno.

\section{CONFLITO DE INTERESSE}

Os autores declaram não haver nenhum tipo de conflito de interesse no desenvolvimento do estudo.

\section{SUPORTE FINANCEIRO}

Fundação de Amparo à Pesquisa do Estado de São Paulo (FAPESP) - Processo no 2006/00360-3.

\section{REFERÊNCIAS}

1. Campbell GL, Marfin AA, Lanciotti RS, Gubler DJ. West Nile virus. Lancet Infect Dis 2002; 2:519-529.

2. Luna EJA, Pereira LE, Souza RP. Encefalite do Nilo Ocidental, nossa próxima epidemia? Epidemiol Serv Saúde 2003; 12:7-19.

3. Dupuis II AP, Marra PP, Kramer LD. Serologic Evidence of West Nile Vírus Transmission, Jamaica, West Indies. Emerging Infect Dis 2003; 9:860-863.

4. Komar O, Robbins MB, Klenk K, Blitvich BJ, Marlenee NL, BurKhalter KL, et al. West Nile Virus Transmission in Resident Birds, Dominican Republic. Emerging Infect Dis 2003; 9:1299-1302.

5. Quirin R, Salas M, Zientara S, Zeller H, Labie J, Murri S, et al. West Nile Vírus, Guadeloupe. Emerging Infect Dis 2004; 10:705-708.

6. Loroño-Pino MA, Blitvich BJ, Farfán-Ale JÁ, Puerto FI, Blanco JM, Marlenee NL, et al. Serologic Evidence of West Nile Vírus Infection in Horses, Yucatan State, México. Emerging Infect Dis 2003; 9:857-859.

7. Giudice PD, Schuffenecker I, Vanderbos F, Counillon E, Zellert H. Human West Nile Virus, France. Emerging Infect Dis 2004; 10:1885-1886.

8. Araújo FAAA, Vianna RST, Wada MY, Silva EV, Doretto L, Cavalcante GC, et al. Inquérito Sorológico em aves migratórias e residentes de Galinhos/RN para detecção do vírus da Febre do Nilo Ocidental e outros vírus. Bol Eletronico Epidemiol 2004; 4:1-12.

9. Araújo FAAA, Vianna RST, Andrade-Filho GV, Melhado DL, Todeschini B, Cavalcante GC, et al. Segundo Inquérito Sorológico em aves migratórias e residentes do Parque Nacional da Lagoa do Peixe/RS para detecção do vírus da Febre do Nilo Ocidental e outros vírus. Bol Eletronico Epidemiol 2004; 4:1-8.

10. Morales MA, Barrandeguy M, Fabbri C, Garcia JB, Vissani A, Trono K, et al. West Nile Virus Isolation from Equines in Argentina, 2006. Emerging Infect Dis 2006; 12:1559-1561.

11. Ministério da Saúde. Coordenação de Vigilância das Doenças Transmitidas por Vetores e Antropozoonoses. Febre do Nilo Ocidental. [Internet] - 2007. [acessado em 20 nov 2007]. Disponível em http://portal.saude.gov.br/portal/ saude/visualizar_texto.cfm?idtxt=27015.

12. Hubálek Z, Halouzka J. West Nile Fever - a Reemerging Mosquito-Borne Viral Disease in Europe. Emerging Infect Dis 1999; 5:643-650.

13. Granwehr BP, Lillibridge KM, Higgs S, Mason PW, Aronson JF, Campbell GL, et al. West Nile Virus: where are we now? Lancet Infect Dis 2004; 4:547-556.

14. Prefeitura Municipal de São José do Rio Preto. Conjuntura econômica de São José do Rio Preto [Internet] - 2007. [acessado em 7 janeiro 2008]. Disponível em http://www.riopreto.sp.gov.br/externos/sm_planejamento/conjuntura economica/2007.pdf.

15. Rezende AA, Ranga NT. Lianas da Estação Ecológica do Noroeste Paulista, São José do Rio Preto, SP, Brasil. Acta Bot Bras 2005; 19:273-279.

16. Daud RD, Feres RJF. Diversidade e Flutuação Populacional de Ácaros (Acari) em Mabea fistulifera Mart. (Euphorbiaceae) de Dois Fragmentos de Mata Estacional Semidecídua em São José do Rio Preto, SP. Neotrop Entomol 2005; 34:191-201. 
17. Forattini OP. Culicidologia Médica. Identificação, biologia, epidemiologia. Vol 2. São Paulo: Editora da Universidade de São Paulo; 2002.

18. Sirivanakarn S. A Review of the Systematics and Proposed Scheme of Internal Classification of New World Subgenus Melanoconion of Culex (Diptera, Culicidae). Mosq Syst 1982; 14:265-333.

19. Reinert JF. Revised list of abbreviations for genera and subgenera of Culicidae (Diptera) and notes on generic and subgeneric changes.J Am Mosq Contr Assoc 2001; 17:51-55.

20. Magurran AE. Ecological Diversity and Its Measurement. Princeton: Princeton University Press; 1988.

21. Zar J K. Biostatistical analisys. New Jersey: Prentice Hall; 1996.

22. Goddard LB, Roth AE, Reisen WK, Scott W. Vector Competence of California Mosquitoes for West Nile virus. Emerging Infect Dis 2002; 8:1385-1391.

23. Savage HM, Smith GC, Moore CG, Mitchell CJ, Townsend M, Marfin AA. Entomologic Investigations of an Epidemic of ST. Louis Encephalitis in Pine Bluff, Arkansas, 1991. Am J Trop Med Hyg 1993; 49:38-45.

24. Kramer LD, Styer LM, Ebel GD. A Global Perspective on the Epidemiology of West Nile Virus. Annu Rev Entomol 2008; 53:61-81.

25. Braga C, Albuquerque MFPM, Morais HM. A produção do conhecimento científico e as políticas de saúde pública: reflexões a partir da ocorrência da filariose na cidade do Recife, Pernambuco, Brasil. Cad Saude Publica 2004; 20:351-361.

26. Mondini A, Cardeal ILS, Lázaro E, Nunes SH, Moreira CC, Rahal P. Saint Louis Encephalitis Vírus, Brazil. Emerging Infect Dis 2007; 13:176-178.

27. Consoli RAGB, Oliveira RL. Principais Mosquitos de Importância Sanitária no Brasil. Rio de Janeiro: Editora FIOCRUZ; 1998.

28. Ahid SMM, Oliveira RL. Mosquitos vetores potenciais de dirofilariose canina na Região Nordeste do Brasil. Rev Saude Publica 1999; 33:560-565.

29. Urbinatti PR, Sendacz S, Natal D. Imaturos de mosquitos (Diptera: Culicidae) em parquet de area metropolitana aberto à visitação pública. Rev Saude Publica $2001 ; 35: 461-466$.

30. Morais SA, Marrelli MT, Natal D. Aspectos da distribuição de Culex (Culex) quinquefasciatus Say (Diptera, Culicidae) na região do rio Pinheiros, na cidade de São Paulo, Estado de São Paulo, Brasil. Rev Bras Entomol 2006; 50:413-418.

31. Aitken THG, Downs WG, Spense L, Jonkers AH. St. Louis Encephalitis Virus Isolations in Trinidad, West Indies, 1953-1962. Am J Trop Med Hyg 1964;13:450-451.

32. Urbinatti PR, Menezes RMT, Natal D. Sazonalidade de Aedes albopictus em área protegida na cidade de São Paulo, Brasil. Rev Saude Publica 2007; 41:478-481.

33. Serpa LLN, Costa KVRM, Voltolini JC, Kakitani I. Variação sazonal de Aedes aegypti e Aedes albopictus no município de Potim, São Paulo. Rev Saude Publica 2006; 40:1101-1105.

34. Turell MJ, O'Guinn ML, Doiim DJ, Jones JW. Vector Competence of North American Mosquitoes (Diptera: Culicidae) for West Nile Virus. J Med Entomol $2001 ; 38: 130-134$.

35. Turell MJ, Dohm DJ, Sardelis MR, O'Guinn ML, Andreadis TG, Blow JA. An Update on the Potential of North American Mosquitoes (Diptera:Culicidae) to Transmit West Nile Virus. J Med Entomol 2005; 42:57-62.

36. Richards SL, Ponnusamy L, Unnasch TR, Hassan HK, Apperson C. HostFeeding Patterns of Aedes albopictus (diptera:Culicidae) in Relation to Availability of Human and Domestic Animals in Suburban Landscapes of Central North Carolina. J Med Entomol 2006; 43:543-551.

37. Gomes AC, Torres AMN, Gutierrez MFC, Lemos FL, Lima MLN, Marins JF, et al. Registro de Aedes albopictus em áreas epizoóticas de febre amarela das Regiões Sudeste e Sul do Brasil (Díptera: Culicidae). Epidemiol Serv Saude 2008; 17:71-76.

38. Chiaravalloti Neto F, Dibo MR, Barbosa AAC, Battigagia M. Aedes albopictus (S) na região de São José do Rio Preto, SP: estudo de sua infestação em área já ocupada pelo Aedes aegypti e discussão de seu papel como possível vetor de dengue e febre amarela. Rev Soc Bras Med Trop 2002; 35:351-357.

39. Secretaria de Estado da Saúde. Centro de Vigilância Epidemiológica "Prof. Alexandre Vranjac” [Internet]. 2007. [acesso em 19 junho 2008]. Disponível em http://www.cve.saude.sp.gov.br/htm/zoo/FA08_BOLINFO_arquivos/ epizootia_em_primatas.htm.
40. Serufo JC, Oca HM, Tavares VA, Souza AM, Rosa RV, Jamal MC, et al. Isolation of dengue vírus type 1 from larvae of Aedes albopictus in Campos Altos City, state of Minas Gerais, Brasil. Mem Inst Oswaldo Cruz 1993; 88:503-504.

41. Pecor EJ, Harbach RE, Peyton EI, Roberts DR, Reiman-Kova E, Manguin S, et al. Mosquito studies in Belize, Central America: Records, Taxonomic Notes, and a Checklist of Species. J Am Mosq Contr Assoc 2002; 18:241-276.

42. Forattini OP, Kakitami I, Massad E, Maruce D. Studies on mosquitoes (Díptera: Culicidae) and anthropic environment. 9. Synantropy and epidemiological vector role of Aedes scapularis in South-Eastern Brazil. Rev Saude Publica $1995 ; 29: 199-207$.

43. Gabaldon A, Ulloa G, Godoy N, Marquez E, Pulido J. Aedeomyia squamipennis (Diptera, Culicidae) vector natural de malaria aviaria en Venezuela. Bol Dir Malariol Sanean Amb 1977; 17:9-13.

44. Dutary BE, Petersen JL, Peralta PH, Tesh RB. Transovarial Transmission of Gamboa virus in a tropical mosquito, Aedeomyia squamipennis. Am J Trop Med Hyg 1989; 40:108-113.

45. Tauil PL. Urbanização e ecologia do dengue. Cad Saude Publica 2001; 17:99-102.

46. Laporta GZ, Urbinatti PR, Natal D. Aspectos ecológicos da população de Culex quinquefasciatus Say (Diptera: Culicidae) em abrigos situados no Parque Ecológico do Tietê, São Paulo, SP. Rev Bras Entomol 2006; 50:125-127. 